\title{
Erratum: Parametric instabilities in 3D periodically focused beams with space charge [Phys. Rev. Accel. Beams 20, 014202 (2017)]
}

\author{
Ingo Hofmann and Oliver Boine-Frankenheim
}

(Received 14 March 2017; published 28 March 2017)

DOI: 10.1103/PhysRevAccelBeams.20.039901

In this paper we have made the statement "We emphasize here that we cannot confirm the assertion of [D. Jeon et al., Nucl. Instrum. Methods Phys. Res., Sect. A 832, 43 (2016)] that the envelope mode is part of the fourth order mode."

We acknowledge the suggestion by D. Jeon et al. that our statement does not reflect what they have intended to say in their article. The intent of their article is to assert the independence of the fourth order resonance from the envelope instability. Furthermore, that the envelope instability is excited from the mismatch generated by the fourth order resonance under conditions, which are quantified in their paper in terms of phase advances.

Published by the American Physical Society under the terms of the Creative Commons Attribution 4.0 International license. Further distribution of this work must maintain attribution to the author(s) and the published articles title, journal citation, and DOI. 